concentrate in patients on vitamin $\mathrm{K}$ antagonists presenting with major bleeding: a randomized, plasma-controlled, phase IIIb study. Circulation 2013;128:1234-43.

\section{Chapter 6.14 Epidemiological data on the use of traditional anticoagulants in cardiovascular disease}

\section{Christina Reith and Colin Baigent}

\section{Summary}

Traditional anticoagulants (e.g. parenteral heparins and oral vitamin $\mathrm{K}$ antagonists (VKAs) such as warfarin (coumadin), acenocoumarol, dicoumarol, phenprocoumon, phenindione, and fluindione) are widely used, including in coronary heart disease (CHD), atrial fibrillation (AF), prosthetic heart valves, and heart failure, and as prophylaxis and treatment for venous thromboembolism (VTE). The parenteral anticoagulants are typically used in acute coronary syndrome (ACS), as initial treatment for VTE, or as bridging therapy perioperatively, while the oral anticoagulants (OACs) form the mainstay of traditional anticoagulant therapy for other indications (Table 6.14.1).

\section{Coronary heart disease}

\section{Guidelines}

Acute coronary syndrome-patients presenting with ST segment elevation: primary percutaneous coronary intervention is the preferred reperfusion strategy in ST-segment elevation myocardial infarction (STEMI), provided it can be performed expeditiously. Recommended periprocedural pharmacotherapy includes dualantiplatelet therapy, and a parenteral anticoagulant. The latter can be any of unfractionated heparin (UFH), the low-molecular-weight heparin (LMWH) enoxaparin, or the hirudin bivalirudin, but fondaparinux (a selective factor Xa inhibitor) is not recommended. ${ }^{1,2}$ Anticoagulation is also recommended in STEMI patients treated with thrombolytic therapy until revascularization (if undertaken), or the duration of the hospital stay, up to 8 days. In this setting, the parenteral anticoagulant may be UFH, enoxaparin, or fondaparinux. ${ }^{1,2}$ Routine use of anticoagulant therapy post percutaneous coronary intervention is not indicated except where there is another clear indication for such use (e.g. AF, a mechanical heart valve, or mural thrombi such as may develop with left ventricular aneurysms after large transmural infarctions ${ }^{1,2}$ ).

Acute coronary syndrome-patients presenting without persistent ST-segment elevation: parenteral anticoagulation is also effective in the setting of non-ST elevation acute coronary syndrome. UFH, enoxaparin, fondaparinux, and bivalirudin may all be used, ${ }^{3,4}$ although fondaparinux is often considered to have the most favourable safety-efficacy profile. ${ }^{4}$ As for STEMI, routine use of anticoagulant therapy post percutaneous coronary intervention is not indicated in the absence of another clear indication.

Table 6.14.1 Use of traditional anticoagulants in cardiovascular disease

\begin{tabular}{|c|c|c|}
\hline Condition & Guidelines & Trends and current use \\
\hline Coronary heart disease & $\begin{array}{l}\text { Parenteral anticoagulant (e.g. heparin) peri-ACS; routine use of } \\
\text { anticoagulant post event or in stable CHD not recommended unless } \\
\text { another clear indication for such use }\end{array}$ & $\begin{array}{l}\text { Significant variability in prescription of parenteral } \\
\text { anticoagulants in acute coronary syndrome; } \\
\text { UFH commonly used, although increasing use of } \\
\text { bivalirudin; significant geographical heterogeneity } \\
\text { in use of traditional OACs pre and post admission } \\
\text { for CHD }\end{array}$ \\
\hline Atrial fibrillation & $\begin{array}{l}\text { OAC therapy used as prophylaxis for cardioembolic stroke in those at risk } \\
\text { of such an event (e.g. as assessed by } \mathrm{CHADS}_{2} \text {, or } \mathrm{CHA}_{2} \mathrm{DS}_{2}-\mathrm{VASc} \text { scores); } \\
\text { parenteral anticoagulants may be used as 'bridging therapy' in AF patients } \\
\text { undergoing procedures requiring interruption of OAC }\end{array}$ & $\begin{array}{l}\text { Both under- and overuse of traditional OACs in } \\
\text { AF an issue; geographical heterogeneity in use }\end{array}$ \\
\hline Prosthetic heart valves & $\begin{array}{l}\text { Traditional OAC therapy recommended in those with mechanical heart } \\
\text { valve prostheses; parenteral anticoagulants may be used as 'bridging } \\
\text { therapy' in patients with mechanical heart valves undergoing procedures } \\
\text { requiring interruption of OAC; paucity of evidence for most appropriate } \\
\text { therapy in those with bioprosthetic valves }\end{array}$ & $\begin{array}{l}\text { Variability in anticoagulation strategies following } \\
\text { bioprosthetic valves }\end{array}$ \\
\hline Heart failure & $\begin{array}{l}\text { Other than in patients with an additional risk factor for cardioembolic } \\
\text { stroke, not recommended }\end{array}$ & $\begin{array}{l}\text { Patients frequently prescribed anticoagulants in } \\
\text { absence of clear indication }\end{array}$ \\
\hline Venous thromboembolism & $\begin{array}{l}\text { Prophylaxis: parenteral anticoagulant (e.g. heparin) in patients at increased } \\
\text { risk of thrombosis unless risk of bleeding outweighs anticipated benefits; } \\
\text { treatment: parenteral anticoagulant overlapping with VKA; in those with } \\
\text { cancer and VTE, use LMWH over VKA }\end{array}$ & $\begin{array}{l}\text { Significant proportion of patients failing to receive } \\
\text { recommended VTE therapy }\end{array}$ \\
\hline
\end{tabular}

CHD, coronary heart disease; LMWH, low-molecular-weight heparin; OAC, oral anticoagulant; STEMI, ST-elevation myocardial infarction; NSTEMI, non-ST-elevation myocardial infarction; $\mathrm{UFH}$, unfractionated heparin; VKA, vitamin K antagonist; VTE, venous thromboembolism. 
Stable coronary heart disease: routine use of OACs is not recommended unless warranted by a separate indication.., 6

\section{Trends and current use}

Use of parenteral anticoagulants in acute coronary syndrome: the Global Registry of Acute Coronary Events (GRACE) multinational coronary disease registry ${ }^{7}$ analysed approximately 23,000 patients hospitalized with non-ST-segment elevation myocardial infarction (NSTEMI) or unstable angina enrolled between 1999 and 2005, showing significant variability in heparin prescribing in acute coronary syndrome, with heparin type and use appearing to be related to timing and use of percutaneous coronary intervention. ${ }^{8}$

In the United States, the National Cardiovascular Data Registry Acute Coronary Treatment and Intervention Outcomes Network Registry-Get With the Guidelines (NCDR ACTION RegistryGWTG: AR-G) ${ }^{9}$ captured data on patients with NSTEMI and STEMI from 2007. Results from approximately 73,000 patients with NSTEMI and approximately 49,000 patients with STEMI showed administration of at least one anticoagulant to $91 \%$ with NSTEMI and $94 \%$ with STEMI. Among patients with STEMI, the most commonly used agent was UFH (66\%), followed by bivalirudin (14\%) and LMWH (8\%). In patients with NSTEMI, UFH was also the most frequently used anticoagulant (42\%), followed by LMWH (27\%) and bivalirudin (13\%). Significant differences were found in anticoagulant use by age, risk factors, concomitant medications, and invasive care. ${ }^{10}$ The same registry examined changes in trends of anticoagulant use from 2007 to 2009, demonstrating an increase in use in both STEMI and NSTEMI patients, and decreased rates of overdosing of UFH and LMWH in NSTEMI patients. ${ }^{11}$ The CathPCI Registry also reported significant changes in anticoagulant patterns among both acute coronary syndrome and non-acute coronary syndrome patients from 2005 to 2009, with increasing use of bivalirudin and decreasing use of $\mathrm{UFH}$, and $\mathrm{LMWH} .{ }^{11}$

Use of OACs pre and post admission for coronary heart disease: the European Action on Secondary and Primary Prevention by Intervention to Reduce Events (EUROASPIRE) surveys examined drug therapies in patients with coronary heart disease. EUROASPIRE-II (1999-2000) reported 7\% of patients as being on an anticoagulant on admission, $12 \%$ at discharge, and $7 \%$ at interview a median of 1.4 years after discharge, with evidence of geographical variation in use. ${ }^{12}$ EUROASPIRE-III (2006-2007) reported $8 \%$ of patients as being on an anticoagulant regimen at discharge and $6 \%$ at subsequent interview at a median of 1.2 years, again with intercountry heterogeneity. ${ }^{13}$ The EURObservational Research Programme Chronic Ischaemic Cardiovascular Disease Registry Pilot phase (CICD-PILOT) registry has been conducted in multiple countries across Europe. From 2013 to 2014, among 2420 patients with non-ST elevation acute coronary syndrome and chronic stable coronary artery disease, or with peripheral artery disease, 9\% were on OACs overall before hospital admission (VKAs in 7\%) with distribution by patient cohort type being: $5 \%$ for acute coronary syndrome undergoing percutaneous coronary intervention; $8 \%$ for chronic stable coronary artery disease undergoing elective percutaneous coronary intervention,
$14 \%$ for stable coronary artery disease, and $14 \%$ for peripheral artery interventions. After discharge/consultation, the corresponding numbers were $11 \%$ overall, distributed as $8 \%, 9 \%, 18 \%$, and $15 \%$ for the different patient cohort types respectively. ${ }^{14}$

\section{Atrial fibrillation}

\section{Guidelines}

AF frequently coexists with other conditions such as hypertension, coronary artery disease, valvular heart disease and heart failure. OAC therapy remains a cornerstone therapy for prevention of cardioembolic stroke in those with AF. Clinical guidelines use risk scores (such as $\mathrm{CHADS}_{2}$, or $\mathrm{CHA}_{2} \mathrm{DS}_{2}$-VASc) to estimate stroke risk in such patients, with a score of 2 or higher indicating that anticoagulation is required. ${ }^{15,16}$ Traditional OAC options include VKAs such as warfarin. Parenteral anticoagulants such as LMWH are sometimes used as 'bridging therapy' to reduce the risk of thromboembolic events in patients with AF undergoing procedures that require $\mathrm{OAC}$ interruption, and has been recommended in those with $\mathrm{AF}$ and mechanical heart valves. ${ }^{15}$ However, in a randomized trial of those with $\mathrm{AF}$ but without a mechanical heart valve, forgoing bridging anticoagulation was found to be noninferior to perioperative bridging with LMWH for the prevention of arterial thromboembolism, and decreased the risk of major bleeding. ${ }^{16,17}=$

\section{Trends and current use}

Extent and type of use: there has been a general increase in the use of OACs for prevention of thromboembolic stroke, ${ }^{18}$ but suboptimal use (both overuse in patients at low risk and underuse in those at high risk) is common. The international Global Anticoagulant Registry in the FIELD (GARFIELD) enrolled patients with newly diagnosed AF and risk factors for stroke $-{ }^{19}$ with enrollment into the first cohort taking place between December 2009 and October 2011 in 19 countries in Europe, Asia-Pacific, Central/South America, and Canada. ${ }^{20}$ Among approximatively 10,000 adults diagnosed with non-valvular atrial fibrillation within the previous 6 weeks, mean $\mathrm{CHADS}_{2}$ score was 1.9 with $57 \%$ having a score of 2 or higher, with corresponding figures for $\mathrm{CHA}_{2} \mathrm{DS}_{2}$-VASc being 3.2 and $84 \%$. However, $38 \%$ of patients with a CHADS 2 score of 2 or higher were not receiving any anticoagulant therapy, whereas $43 \%$ of those at low risk (score 0 ) received it. ${ }^{20}$ The Global Registry on Long-Term Oral Antithrombotic Treatment in Patients with Atrial Fibrillation (GLORIA-AF), comprises three phases: Phase I, before the introduction of novel oral anticoagulants (NOACs); Phase II, during the time of the introduction of dabigatran, the first NOAC; and Phase III, once NOACs established in routine practice, involving patients with newly diagnosed non-valvular AF at risk for stroke. This reported the majority of patients in phase I using VKAs as having a high stroke risk $\left(\mathrm{CHA}_{2} \mathrm{DS}_{2}-\mathrm{VASc} \geq 2\right)$, being highest for those with persistent/permanent (as opposed to paroxysmal) $\mathrm{AF}^{21}$ but significantly lower use of VKAs in China, where most patients either received antiplatelet agents or no antithrombotic treatment. In phase II, overall, whilst most patients received some form of anticoagulant therapy, $12 \%$ were reported as receiving antiplatelet treatment and $8 \%$ no antithrombotic treatment, while 
among patients with a $\mathrm{CHA}_{2} \mathrm{DS}_{2}$-VASc score of 2 or higher, $7 \%$ received no antithrombotic treatment and $10 \%$ received aspirin. ${ }^{22}$ Other registries have reported similar underuse of OACs. ${ }^{20,23-25}$ although rapid implementation of guidelines would appear to have an positive impact on appropriate use. ${ }^{26}$ Overuse of OACs is also an issue, ${ }^{20,26}$ with the Practice Innovation and Clinical Excellence (PINNACLE) registry reporting approximately one in four AF patients at low thromboembolic risk being treated with an OAC. ${ }^{27}$

Variation in prescription according to age and sex: underprescribing of OACs in AF is an issue in elderly patients. ${ }^{18,28}$ The GARFIELD registry reported similar use of VKAs ${ }^{29}$ for stroke prevention in men and women with non-valvular AF, with the EurObservational Research Programme Pilot survey on Atrial Fibrillation (EORP-AF) equally reporting overall rates of anticoagulant use to be no different in men and women, with respective use of VKAs and UFH/ LMWH at diagnosis approximately $50 \%$, and $10 \%{ }^{30}$

Geographical variation in prescription: while the EORP-AF Pilot General Registry showed OAC use (either as OAC or OAC plus antiplatelet therapy) in European countries to be broadly similar (ranging from $72 \%$ to $76 \%$ ), ${ }^{31}$ the PREvention oF Thromboembolic EventsEuropean Registry in Atrial Fibrillation (PREFER in AF) showed substantial intercountry differences, with the proportion of patients taking VKAs varying between $86 \%$ (France) and 71\% (Italy). The type of VKA used also varied, with warfarin being used predominantly in the United Kingdom and Italy (75\% and 62\%, respectively), phenprocoumon in Germany (74\%), acenocoumarol in Spain (67\%), and fluindione in France (62\%). ${ }^{32}$ Within phase II of the GLORIAAF registry following the approval of dabigatran, VKA treatment was used in 38\% of patients in Europe, $26 \%$ in North America, and $32 \%$ in Asia, with 22 only $61 \%$ of patients with high stroke risk in Asia receiving OACs, with this low prescription rate being mirrored in the Fushimi AF registry of approximately 3200 community-based AF patients in whom warfarin was prescribed in only $49 \%$ of patients, whereas antiplatelet drugs, mainly aspirin, were prescribed for more than $30 \%$ of the patients. ${ }^{33}$ Similarly, the Registry on Cardiac Rhythm Disorders Assessing the Control of Atrial Fibrillation (RECORD-AF) registry has reported a regional lack of consistency in the use of OACs, with use of OACs in Eastern Europe being significantly lower compared to the other regions, with over half of patients (55\%) in Eastern Europe with a $\mathrm{CHADS}_{2}$ score of 2 or higher using aspirin alone or with other antiplatelet agents. In contrast, it shows greater use of OACs in North America and Western Europe compared to Eastern Europe in patients with a low $\mathrm{CHADS}_{2}$ score. ${ }^{23}$

\section{Prosthetic heart valves}

\section{Guidelines}

Oral anticoagulation with a VKA is recommended for all patients with mechanical heart valve prostheses, with the target median international normalized ratio depending on patient-related risk factors and prosthesis thrombogenicity. ${ }^{34,35}$ However, there is some variation in the guidelines with respect to the indications for combination of low-dose aspirin with a VKA in this setting,with this being recommended for any type of mechanical prosthesis in the American Heart Association/American College of Cardiology guidelines, ${ }^{35}$ whereas the European Society of Cardiology guidelines are more restrictive. ${ }^{34,36}$

Where bridging therapy is required due to interruption of VKA therapy (e.g. perioperatively for major surgery) for those with mechanical heart valves, UFH or LMWH is recommended. ${ }^{34,35}$ There has been some debate about prevention of thromboembolic events in those with bioprosthetic valve replacements. ${ }^{37}$ This may be considered for the first 3 months after implantation of acertain bioprostheses, 34,35 although aspirin is also thought to be reasonable after a bioprosthetic aortic ${ }^{34,35}$ or mitral ${ }^{35}$ valve replacement. Anticoagulation is also recommended for those with bioprostheses who have another indication for anticoagulation (e.g. AF). ${ }^{34,35}$ For those who have undergone transaortic valve implantation (TAVI), there is a paucity of evidence, but dual-antiplatelet therapy and VKAs may be used. ${ }^{34,35}$

\section{Trends and current use}

Results from the Anticoagulation Treatment Influence on Postoperative Patients (ACTION) registry survey showed wide variation of antithrombotic use after bioprosthetic aortic valve replacement, ${ }^{38}$ with $43 \%$ of centres prescribing a VKA, $20 \%$ prescribing VKA and aspirin, $33 \%$ prescribing only aspirin, and $4 \%$ not prescribing any therapy after bioprosthetic aortic valve replacement. Variability in anticoagulation strategies following bioprosthetic valve replacement has also been reported by the ANticoagulation Strategy With Bioprosthetic Valves Post-Operative Event Registry (ANSWER) registry. ${ }^{39}$ The International Valvular Heart Disease II (VHDII) survey will afford more insight into anticoagulant management of patients after a valve intervention. ${ }^{40}$

\section{Heart failure}

\section{Guidelines}

Heart failure is associated with an increased risk of VTE and cardioembolic stroke. However, other than in patients with AF, a mechanical heart valve or an additional risk factor for cardioembolic stroke such as mural thrombi in association with a left ventricular aneurysm, ${ }^{1}$ OAC therapy does not appear to provide an overall benefit compared with placebo or aspirin in patients with heart failure in sinus rhythm, ${ }^{41-44}$ and these treatments are not recommended in this population. ${ }^{45,46}$

\section{Trends and current use}

Among 12,440 patients in the European Society of Cardiology Heart Failure Long-Term Registry (ESC-HF-LT) from 2011 to $2013,31 \%$ of patients with acute heart failure were on an OAC prior to hospitalization and $42 \%$ at discharge, while in the chronic heart failure outpatient setting, $42 \%$ were on OACs. ${ }^{47}$ More recent data show such OAC use to be relatively stable. ${ }^{48}$

Despite guideline recommendations, patients with heart failure are frequently prescribed anticoagulants in the absence of a clear indication. The American Heart Association's Get With The Guidelines-Heart Failure (GWTG-HF) Registry among approximately 66,000 heart failure patients reported warfarin being 
prescribed at discharge in approximately $11 \%$ without an established indication for anticoagulation. There was also substantial variation in warfarin prescription between hospitals, ranging from $0 \%$ to $45 \% .{ }^{49}$ Data from the Acute Decompensated Heart Failure National Registry (ADHERE) reported approximately 9\% of patients aged 65 years or older who were not on anticoagulation prior to admission with no concurrent $\mathrm{AF}$ as receiving such therapy at discharge. ${ }^{50}$ Other studies have shown even higher rates (29\%) of warfarin use in patients with advanced chronic systolic heart failure without $\mathrm{AF}$, prior thromboembolic events, or prosthetic valves. ${ }^{51}$

\section{Venous thromboembolism}

\section{Guidelines}

VTE encompasses the conditions of deep venous thrombosis and pulmonary embolism, with pulmonary embolism most commonly being a consequence of deep venous thrombosis. Traditional anticoagulants are used in both the treatment and prevention of this condition.

VTE prophylaxis: prophylactic heparin (LMWH, fondaparinux, or UFH) is recommended in patients at increased risk of thrombosis (such as surgical, hospitalized, medical and cancer patients) unless the assessed risk of bleeding outweighs the anticipated benefits. Prophylaxis should be continued until the patient is no longer thought to be at increased risk of VTE. ${ }^{52-54}$

VTE treatment: patients who present with symptomatic deep venous thrombosis or pulmonary embolism have traditionally been treated with a parenteral anticoagulant such as a heparin (e.g. UFH, LMWH, or fondaparinux) for at least 5 days overlapping with the initiation of a VKA until the international normalized ratio has been greater than or equal to 2.0 for at least 24 hours/two consecutive days. The VKA should then be maintained for at least 3 months, with the decision to extend therapy based upon the individual patient's risk of recurrence versus bleeding risk. ${ }^{55-58}$ LMWH or fondaparinux is preferred over UFH for initial anticoagulation in pulmonary embolism, since they carry a lower risk of major bleeding and heparininduced thrombocytopenia. However, UFH is recommended for patients in whom primary reperfusion is considered, as well as for those with serious renal impairment (creatinine clearance $<30 \mathrm{~mL}$ / $\min$ ), or severe obesity, due to its short half-life, the ability to monitor its effects, and its rapid reversibility with protamine. ${ }^{55}$ Non-heparinoid anticoagulants such as danaparoid, lepirudin, argatroban, or bivalirudin may be used for patients with suspected or confirmed heparin-induced thrombocytopenia. ${ }^{57,59}$ In those with cancer and VTE, LMWH is recommended over VKA. ${ }^{55-58}$

\section{Trends and current use}

Registry data indicate that a significant proportion of patients fail to receive recommended VTE therapy.

For example, in relation to prophylaxis, the Epidemiologic International Day for the Evaluation of Patients at Risk for Venous Thromboembolism in the Acute Hospital Care Setting (ENDORSE) registry enrolled approximately 68,000 hospital in patients between 2006 and 2007 across 32 countries in six continents, and reported only $40 \%$ of approximately 15,500 medical patients and 59\% of approximately 20,000 surgical patients at risk for VTE as receiving guideline recommended VTE prophylaxis. ${ }^{60}$ This registry has also shown that in medical patients, prophylaxis use appears to be associated with disease severity rather than medical diagnosis, ${ }^{61}$ and in surgical patients, prophylaxis use varies according to major surgery type from $86 \%$ for orthopaedic surgery to $54 \%$ in urological/ gynaecological and other procedures. ${ }^{62}$ The International Medical Prevention Registry on Venous Thromboembolism (IMPROVE) also assessed VTE prophylaxis in approximately 15,000 acutely ill hospitalized medical patients enrolled from 2002 to 2006, reporting that only about $60 \%$ of patients who were eligible for receiving prophylaxis actually received it. There was also wide variation in practice, with $33 \%$ of patients in the United States and $47 \%$ of patients in other countries receiving VTE prophylaxis with LMWH or UFH, with UFH being used most frequently used in the United States (21\%), and LMWH in other participating countries including Australia, Brazil, Canada, Columbia, France, Germany, Italy, Japan, Spain, the United Kingdom, and Venezuela (40\%). ${ }^{63}$ Evidence of suboptimal prophylactic therapy has also been reported in other registries such as the Global Orthopaedic Registry (GLORY). ${ }^{64}$

In the context of treatment of VTE, the RIETE (Registro Informatizado de Enfermedad TromboEmbólica) multinational registry of patients with symptomatic, objectively confirmed, acute VTE in Europe has assessed use of anticoagulants in both patients with and without cancer. Long-term VKA monotherapy was reported as being received by $82 \%$ of more than 35,000 patients without cancer (but $17 \%$ started after the first week), and $66 \%$ of approximately 4400 patients with cancer received long term LMWH as monotherapy. ${ }^{65}$ The PREFER in VTE international registry assessed patients with acute VTE between January 2013 and July 2015 in primary and secondary care across seven European countries. This reported $73 \%$ of patients receiving initial therapy with heparin and almost half receiving a VKA (and a quarter receiving one of the newer direct acting oral anticoagulants) following the index event. ${ }^{66}$

The GARFIELD-VTE multinational registry will provide further valuable insight into the characteristics and management of patients with VTE. ${ }^{67}$

\section{Conclusion}

Traditional anticoagulants are widely used in cardiovascular disease. Parenteral anticoagulants are routinely used in acute coronary syndrome, VTE, or as bridging therapy, whereas long-term use of traditional OACs is principally in the context of prophylaxis of cardioembolism in AF and in those with mechanical heart valves. However, the use of OACs in accordance with clinical guidelines remains suboptimal, with substantial intercountry variation.

\section{Online resources}

$\rightarrow$ For full references and multimedia materials please visit the online version of the book (http://www.oup.com/esccardiomed). 


\section{Further reading}

Cohen AT, Tapson VF, Bergmann JF, Goldhaber SZ, Kakkar AK, Deslandes B, Huang W, Zayaruzny M, Emery L, Anderson FA Jr; ENDORSE Investigators. Venous thromboembolism risk and prophylaxis in the acute hospital care setting (ENDORSE study): a multinational cross-sectional study. Lancet 2008;371:387-94.

Eapen ZJ, Grau-Sepulveda MV, Fonarow GC, Heidenreich PA, Peterson ED, Hernandez AF. Prescribing warfarin at discharge for heart failure patients: findings from the Get With The Guidelines-Heart Failure Registry. Int J Cardiol 2014;172:e322-3.

Gore JM, Spencer FA, Goldberg RJ, Kennelly BM, Fox KA, Allegrone J, Eagle KA, Anderson FA Jr, Steg PG; GRACE Investigators. Use of heparins in non-ST-elevation acute coronary syndromes. Am J Med 2007;120:63-71.11.

Huisman MV, Ma CS, Diener HC, Dubner SJ, Halperin JL, Rothman KJ, Teutsch C, Schoof N, Kleine E, Bartels DB, Lip GY; GLORIAAF Investigators. Antithrombotic therapy use in patients with atrial fibrillation before the era of non-vitamin $\mathrm{K}$ antagonist oral anticoagulants: the Global Registry on Long-Term Oral Antithrombotic Treatment in Patients with Atrial Fibrillation (GLORIA-AF) Phase I cohort. Europace 2016;18:1308-18.

Huisman MV, Rothman KJ, Paquette M, Teutsch C, Diener HC, Dubner SJ, Halperin JL, Ma CS, Zint K, Elsaesser A, Bartels DB, Lip GY; GLORIA-AF Investigators. Antithrombotic treatment patterns in patients with newly diagnosed nonvalvular atrial fibrillation: the GLORIA-AF Registry, Phase II. Am J Med 2015;128:1306-13.

Kakkar AK, Mueller I, Bassand JP, Fitzmaurice DA, Goldhaber SZ, Goto S, Haas S, Hacke W, Lip GY, Mantovani LG, Turpie AG, van Eickels M, Misselwitz F, Rushton-Smith S, Kayani G, Wilkinson P, Verheugt FW; GARFIELD Registry Investigators. Risk profiles and antithrombotic treatment of patients newly diagnosed with atrial fibrillation at risk of stroke: perspectives from the international, observational, prospective GARFIELD registry. PloS One 2013;8:e63479.
Komajda M, Weidinger F, Kerneis M, Cosentino F, Cremonesi A, Ferrari R, Kownator S, Steg PG, Tavazzi L, Valgimigli M, Szwed H, Majda W, Olivari Z, Van Belle E, Shlyakhto EV, Mintale I, Slapikas R, Rittger H, Mendes M, Tsioufis C, Balanescu S, Laroche C, Maggioni AP. EURObservational Research Programme: the Chronic Ischaemic Cardiovascular Disease Registry: Pilot phase (CICD-PILOT). Eur Heart J 2016;37:152-60.

Kotseva K, Wood D, De Backer G, De Bacquer D, Pyörälä K, Keil U; EUROASPIRE Study Group. EUROASPIRE III: a survey on the lifestyle, risk factors and use of cardioprotective drug therapies in coronary patients from 22 European countries. Eur J Cardiovasc Prev Rehabil 2009;16:121-37.

Lip GY, Laroche C, Boriani G, Dan GA, Santini M, Kalarus Z, Rasmussen LH, Oliveira MM, Mairesse G, Crijns HJ, Simantirakis E, Atar D, Maggioni AP, Tavazzi L. Regional differences in presentation and treatment of patients with atrial fibrillation in Europe: a report from the EURObservational Research Programme Atrial Fibrillation (EORP-AF) Pilot General Registry. Europace 2015;17:194-206.

MaggioniAP, AnkerSD, Dahlström U, Filippatos G, PonikowskiP,Zannad F, Amir O, Chioncel O, Leiro MC, Drozdz J, Erglis A, Fazlibegovic E, Fonseca C, Fruhwald F, Gatzov P, Goncalvesova E, Hassanein M, Hradec J, Kavoliuniene A, Lainscak M, Logeart D, Merkely B, Metra M, Persson H, Seferovic P, Temizhan A, Tousoulis D, Tavazzi L; Heart Failure Association of the ESC. Are hospitalized or ambulatory patients with heart failure treated in accordance with European Society of Cardiology guidelines? Evidence from 12,440 patients of the ESC Heart Failure Long-Term Registry. Eur J Heart Fail 2013;15:1173-84.

Roe MT, Messenger JC, Weintraub WS, Cannon CP, Fonarow GC, Dai D, Chen AY, Klein LW, Masoudi FA, McKay C, Hewitt K, Brindis RG, Peterson ED, Rumsfeld JS. Treatments, trends, and outcomes of acute myocardial infarction and percutaneous coronary intervention. J Am Coll Cardiol 2010;56:254-63. 